\title{
Pectus Excavatum: A Historical Perspective and a New Metal-Free Procedure
}

\author{
Akira Masaoka and Satoshi Kondo \\ Department of Oncology, Immunology and Surgery, \\ Nagoya City University Graduate School of Medical Sciences,
}

Japan

\section{Introduction}

\subsection{Epidemiology and etiology/pathogenesis}

Pectus excavatum (PE) is a most frequent deformity at the anterior chest wall. Its incidence is about 1:400 in live births. Male to female ratio is 4:1. Various theories have been proposed to explain pathogenesis of PE.

Brown (Brown, 1939) described that the force producing the depression is diaphragm acting primarily in the anteroposterior direction through its attachment to the sternum. He pointed out a membranous structure beneath the sternum, and denominated it substernal ligament.

On the other hand, Sweet (Sweet, 1944) thought that the substernal ligament is not important structure, and stated "it seems almost as though the sternum is pushed down against spine by unusually long, inward curving costal cartilages".

This idea evoked sympathy of many surgeons, and the overgrowth of cartilages theory for PE became the leading theory, because of significance of theoretical background for the surgeon's act to resect the overgrown cartilages.

However, recently, Nakaoka and colleagues (Nakaoka et al., 2009, 2010) measured the length of the 5th and 6th costal cartilages and ribs in PE patients from reconstructed images of 3-dimensional computed tomography (CT). He calculated the $C / R$ ratio, defined as the quotient of the costal cartilage length divided by the adjacent rib length, and compared it between the PE patients and the healthy controls. As the result, he found that the $C / R$ ratio in the PE patients were not longer than that in the healthy controls at any level, so concluded that the overgrowth of costal cartilages is not the pathogenesis of PE.

PE patients often show characteristic figure, such as lanky shape, and thin thorax, and associate sometimes Marfan syndrome or Noonan syndrome. These findings suggest hereditary origin of PE.

Creswick and colleagues (Creswick et al., 2006) analysed 34 families and assumed autosomal dominant inheritance in 14 families, autosomal recessive inheritance in 4 families, and X-chromosomal inheritance in 6 families. However, many family members had additional connective tissue traits, that is, systemic connective tissue diseases can not be ruled out.

Marfan syndrome occurs in 1:5,000 to 10,000 of population. It is genetic disease, which is caused by mutation in the Fibrillin 1 gene localized on the long arm of chromosome 15. 
On the other hand, Noonan syndrome is a common autosomal dominantly inherited disorder caused by mutations in various genes (PTPN 11, KRAS, SOS1, RAF1). Incidence is 1:1,000 to 2,500 (Kotzot \& Schwabegger, 2009).

However, causative genes of isolated (non syndromic) PE are not yet determined. PE can be an isolated malformation or dysmorphic feature or only one symptom of a genetic syndrome. The research of responsible gene relating with PE is yet on the start line.

\subsection{Symptomatology}

PE is a deformity of the thorax characterized by depression of the sternum. The cephalic border of the depression situates usually at the conjunction of manubrium and sternal body. The sternal body leans sharply to the depth, deepest just before its junction with the xiphoid. The lower costal cartilages bend inward to form depression.

In infant, a paradoxical inward motion of the lower sternum is conspicuous on inspiration. PE becomes fixed at child age (2 3 years). Eguchi and colleagues (Eguchi et al., 1993) observed natural course of the PE deformity in 25 patients (average 2.5 years). Mean period of observation was 3.2 years. Ten patients (40\%) progressed, $14(56 \%)$ did not change, and one $(4 \%)$ patient improved. In the progressed patients, 5 patients showed asymmetrical progression. These results suggest some clinical implications, i.e., 1) decision of operative indication should be delayed until schoolchild age at least, 2) asymmetry starts already at child age.

Usually, deformity is going to progress together with growth. At puberty, growth of the thorax spurts. The characteristic of progression in this term is reinforce of asymmetry, characterizing deeper depression at right side and torsion of the sternum. Such asymmetric deformity is considered to be resulted from existence of heart in left side.

PE deformity is not common in all patients. There are some types with typical different features. Nuss (Nuss, 2008) expressed as cup shape, saucer shape and Grand Canyon shape. Cup shape means a localized, narrow depression (Fig. 1). Saucer shape is a wide and flat depression (Fig. 2). Grand Canyon shape means asymmetric type with deepest at right side (Fig. 3). Moreover, each patient shows different grade. In order to express objectively the characteristic of each patient, various deformity indices of PE have been proposed.

Introduction of computerized tomography (CT) enhanced such trend. Haller and colleagues (Haller et al., 1987) set transverse diameter/anterior-posterior diameter as an index. The anterior-posterior diameter means a distance between sternum and spine at the deepest depression level. He stated that this index was $4.42 \pm 0.76$ in PE patients and $2.56 \pm 0.35$ in normal subjects, and useful in judgment of operative indication.

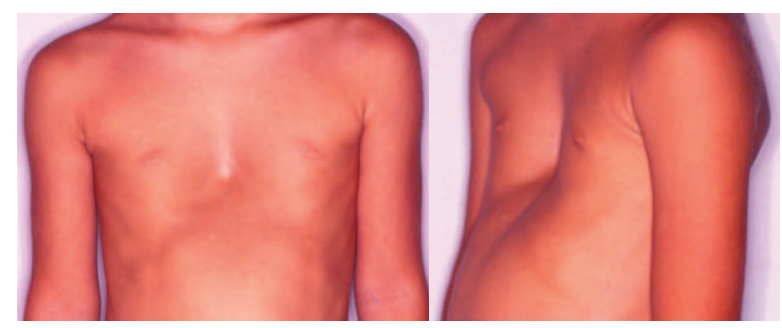

Fig. 1. Cup shape depression 

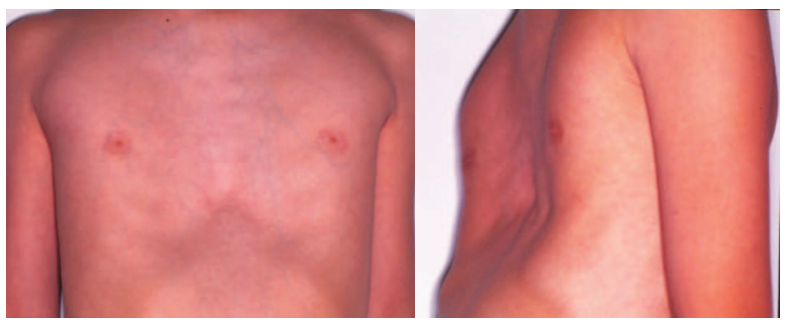

Fig. 2. Saucer shape depression
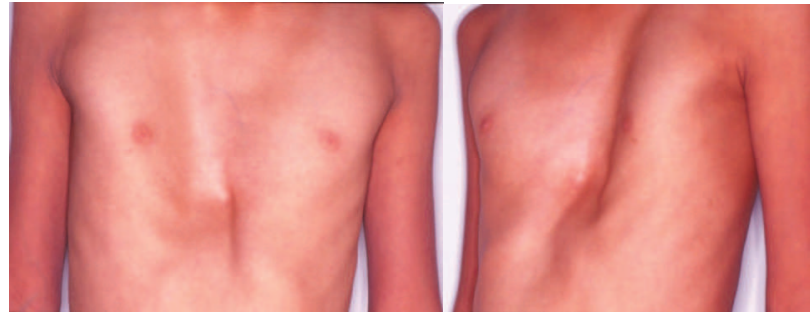

Fig. 3. Grand Canyon shape depression

Nakahara and colleagues (Nakahara et al., 1987) set 3 indices; degree of depression, degree of asymmetry, and degree of flatness (Fig. 4). These indices serve to define the diagnosis, to decide operative indication, and evaluate the effects of operation.

Masaoka and colleagues (Masaoka et al., 2011) proposed 3 other indices; steepness index, excavation volume index, and asymmetry index. These are defined as shown in Fig. 5. This system has properties described below.

1. Three indices express the morphological characteristic in PE straight, respectively. Steepness index represents cup shape, excavation volume index saucer shape, and asymmetry index Grand Canyon shape configuration.

2. Excavation volume index and asymmetry index are defined two-dimensionally, in order to quantify more exactly.

$$
\text { Haller's index }=\frac{\mathrm{a}}{\mathrm{c}}
$$

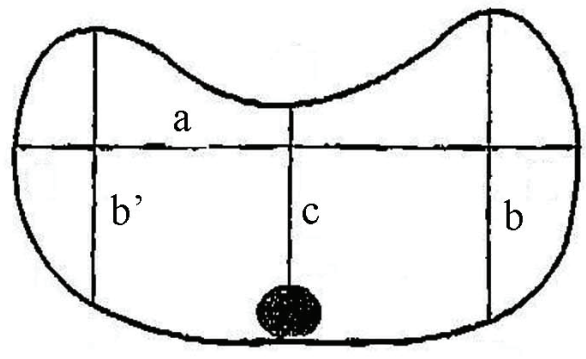

degree of depression $=\frac{b}{c}$

degree of asymmetry $=\frac{b^{\prime}}{b}$

degree of flatness $=\frac{a}{b}$

Fig. 4. Deformity indices (Nakahara et al., 1987) 


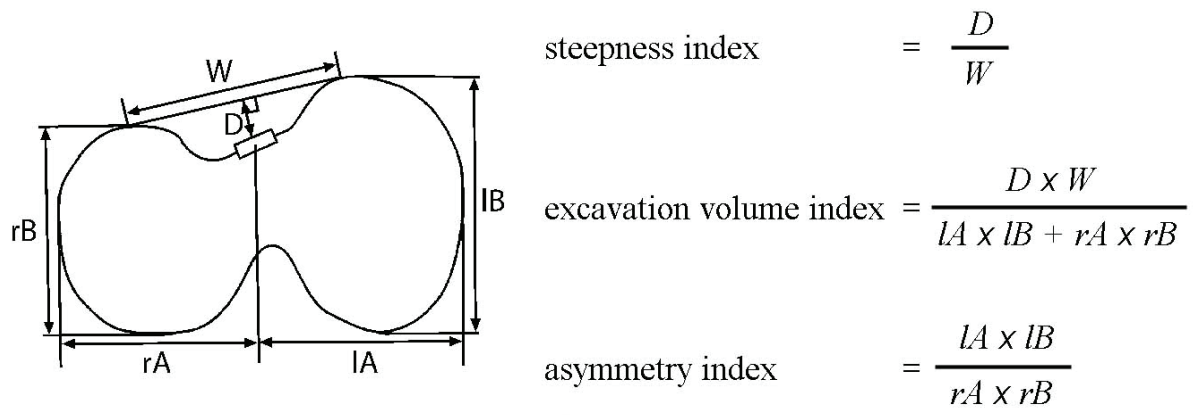

Fig. 5. Deformity indices (Masaoka et al., in press)

(Reprinted with permission from Eur J Cardiothorac Surg 2011, in press)

PE is a symptomatic disease. Kelly (Kelly, 2008) investigated medical history of 327 PE patients (Table 1). Various symptoms with high percentages are listed up. Representatives are exercise intolerance, lack of endurance, shortness of breath, chest pain etc. Marfan syndrome (4.6\%) and Ehlers-Danlos syndrome (2.8\%) are associated with PE. Additionally, association of various psychological disturbances is pointed out, such as self-consciousness about chest, withdrawal from social and sports activities, depression even to suicide.

\begin{tabular}{|l|c|c|}
\hline \multicolumn{1}{|c|}{ Condition } & Number & Percentage \\
\hline Exercise intolerance & 211 & 64.5 \\
\hline Lack of endurance & 205 & 62.7 \\
\hline Shortness of breath & 203 & 62.1 \\
\hline Chest pain with exercise & 167 & 51.1 \\
\hline Family history of PE & 140 & 42.8 \\
\hline Chest pain without exercise & 104 & 31.8 \\
\hline Asthma & 70 & 21.4 \\
\hline Scoliosis & 69 & 21.1 \\
\hline Cardiac abnormalities & 65 & 19.9 \\
\hline Frequent or prolonged URI & 44 & 13.5 \\
\hline Palpitations & 37 & 11.3 \\
\hline Pneumonia & 28 & 8.6 \\
\hline Fainting/dizziness & 27 & 8.3 \\
\hline Marfan syndrome & 15 & 4.6 \\
\hline Family history of PC & 13 & 4.0 \\
\hline Ehlers-Danlos syndrome & 9 & 2.8 \\
\hline Family history of Marfan syndrome & 8 & 2.4 \\
\hline Patient adopted & 4 & 1.2 \\
\hline Patient has identical twin & 3 & 0.9 \\
\hline Family history of Ehlers-Danlos syndrome & 2 & 0.6 \\
\hline Sprengel deformity & 2 & 0.6 \\
\hline
\end{tabular}

Abbreviations: PC, pectus carinatum; URI, upper respiratory infection.

Table 1. Medical history of 327 patients (Kelly, 2008)

(Reprinted with permission from Semin Pediatr Surg 2008; 17;189) 


\subsection{Physiology}

PE causes compression of lung and heart, which might result in impairment of respiratory and circulatory function. The impairment of these functions is sometimes too modest to be evaluated by usual function tests preoperatively, in spite of existence of subjective symptoms. In order to recognize relationship between the results of the examinations and PE deformity, it is important to confirm, 1) difference between those of the PE patients and the healthy controls, 2) relationship with the severity of deformity, and 3) improvement by surgical repair. Clinically, the results of such examinations could be parameters to evaluate the effects of surgeries.

\subsubsection{Respiratory function}

Since 1950's, many papers on this topic have been published. In early years, measurement of conventional standard pulmonary volumes by spirometer was only one tool. Thereafter, flow-volume curve by pneumotachograph, TLC (Table 2) and RV by nitrogen washout, or body plethysmograph, and various work load tests were adopted. However, there are various opinions concerning what is the representative parameter expressing decreased pulmonary function due to PE deformity.

\begin{tabular}{|l|l|}
\hline TLC & total lung capacity \\
\hline RV & residual volume \\
\hline MVV & maximal ventilation volume \\
\hline FVC & forced ventilatory capacity \\
\hline FEV & forced expiratory volume \\
\hline FEV $_{1}$ & forced expiratory volume in 1 second \\
\hline FEF $_{25 \% ~ 75 \%}$ & forced expiratory flow from $25 \%$ exhalation to $75 \%$ exhalation \\
\hline RV & right ventricle \\
\hline RVSD & right ventricle short distance \\
\hline PWC & physical work capacity \\
\hline SV & stroke volume \\
\hline
\end{tabular}

Table 2. List of abbreviations

In early years, MVV was thought to be a most reliable parameter to assess the reduced pulmonary function. Haller and colleague (Haller \& Loughlin, 2000) pointed out significant difference of TLC, FVC, and RV between the PE patients and the matched controls. Nuss and colleague (Nuss \& Kelly, 2008) stated that FVC, $\mathrm{FEV}_{1}, \mathrm{FEF}_{25 \%-75 \%}$ reduced in the PE patients, comparing with the age-, height-matched predictive values. Which spirometrical parameter is definitely different between the PE patients and the controls are not agreed in various papers. Castile and colleagues (Castile et al., 1982) reported that in the symptomatic PE patients, the measured oxygen uptake increasingly exceeded the predicted value as the work loads approached maximum, different from healthy controls. Haller and colleague (Haller \& Loughlin, 2000) did not find difference of $\mathrm{O}_{2}$ pulse $\left(\mathrm{O}_{2}\right.$ consumption/heart rate) after treadmill works between the PE patients and the controls. On the other hand, Malek and colleagues (Malek et al, 2003) reported that the $\mathrm{O}_{2}$ pulse on maximal exercise testing was significantly lower than the reference value, and furthermore, this limitation was caused by cardiovascular factor, but not ventilatory.

As for the relationship between decreased pulmonary function and severity of deformity, Lawson and colleagues (Lawson et al., 2011), after investigation of 310 PE patients, reported that the percentages of the patients with abnormal $\mathrm{FVC}, \mathrm{FEV}_{1}, \mathrm{FEF}_{25 \%}-75 \%$, and TLC data 
increased with increasing Haller index. He speculated that the large tidal volume required by exercise causes some of the symptoms by the effects of deformity on rib motion and bellows function.

Comparison of the results of pulmonary function tests in preoperative and postoperative period was performed Cahill and colleagues (Cahill et al., 1984). He pointed out significant improvement of MVV, and improvement in exercise performance as quantified by maximal $\mathrm{O}_{2}$ consumption. Haller and colleague (Haller \& Loughlin, 2000) recognized a higher $\mathrm{O}_{2}$ pulse in exercising tests in postoperative patients. Nuss and colleague (Nuss \& Kelly, 2008) pointed out normalization of $\mathrm{FEV}_{1}, \mathrm{TLC}$, and diffusing lung capacity. Lawson and colleagues (Lawson et al., 2005) found that FVC, $\mathrm{FEV}_{1}$, and $\mathrm{FEF}_{25 \%-75 \%}$ were lower than normal preoperatively, and small but significant improvement of these 3 parameters after the Nuss surgeries and bar removals.

The above-described data about relationship between pulmonary function and PE deformity from many articles are summarized to be unfixed, because conduct of spirometrical test is difficult in child, and comparison of preoperative and postoperative data is difficult due to growth.

\subsubsection{Cardiovascular function}

Assessment of the cardiovascular function in PE began with introduction of cardiac catheterization. The hemodynamics measured at rest revealed normal pattern in majority of the early papers. However, Fabricius and colleagues (Fabricius et al., 1957) recognized abnormal high right atrial pressure in 3, and increased right ventricular pressure in one, after examinations of 26 patients.

Introduction of angiocardiography clarified dysmorphology of heart by dislocation or compression, i.e., anterior rotation of right atrium and compression on right lateral wall. CT scan substituted the angiocardiography, and verified noninvasively mitral valve prolapse and sternal imprint on the anterior wall of the right ventricle (Shamberger et al., 1987).

Radioisotope angiography appeared as a substitute of cardiac catheterization or angiography with contrast material. Shamberger and Welch performed this examination in 25 cases, and pointed out enlarged right atrium in 15, enlarged right ventricle in 15, dilated pulmonary artery in 10, delayed pulmonary artery transit time in 11, decreased left ventricular volume in 9, and compression defect in the right ventricle in 8 (Shamberger \& Welch, 1988).

On the other hand, cardiac catheterization on exercise added new informations. Bevegard (Bevegard, 1962) performed right heart catheterization in 16 patients and found that the patients with severe PE showed 20\% decrease of PWC (Table 2) from the supine position to the sitting position, similar to that of the normal subjects. But, increase of SV from rest to exercise was only $18.5 \%$, much less than the $51 \%$ increase in the normal subjects. This finding could be an evidence of the exercise-induced symptoms in the PE patients.

Peterson and colleagues (Peterson et al., 1985) assessed cardiac volume and output with radionuclide angiography in 13 patients, and compared those data in preoperative and postoperative period. He found that the right ventricular ejection fraction at rest decreased after repair, which could be attributed to the increase of the right ventricular and diastolic volume index after operation. However, cardiac index did not increase significantly after operation at rest or during exercise.

Recently, cardiovascular resonance imaging was introduced to this field. Saleh and colleagues (Saleh et al., 2010) examined this test in 30 patients, and found reduction of RV ejection fraction and RVSD both at end diastole and systole. 
In summary, compression of the right heart leads to diminished stroke volume, and in accordance with the modest decrease of ventilatory activity, leads to diminished cardiopulmonary capacity in severe PE patients. Repair surgery for PE could improve cardiorespiratory function in the patients with impaired function.

\section{Corrective surgery for pectus excavatum}

\subsection{Overview}

Surgical correction for PE started at early 20th century, but could not gain successful results. The pioneer to open the curtain to modern era of the corrective surgery for PE was Brown (Brown 1939). Observing inward retraction of the xiphoid in baby's crying, he thought that the retraction is caused by the traction of diaphragm, and speculated that the substance of it could be the substernal ligament and the transverse thoracic muscle which combine the diaphragm with the sternum. Furthermore, he speculated that delay of such condition in infancy could lead to the definite thoracic deformity in adult.

So, he thought up two procedures. The 1st was indicated to infant or little child. The core of the procedure is to dissect the substernal ligament and/or the attachment to diaphragm under a small, vertical incision at level of the xiphoid. He expected that such procedure could prevent to proceed to the definitive PE deformity in adult.

The 2 nd was indicated to elder child, adolescent and adult. The core of this procedure is 1) resection of $2 \mathrm{~cm}$ costo-chondral segments of the 4 th 7 th ribs near the junction with the sternum, and 2) wedge resection of the sternum on the anterior table at level of junction of the sternal body and the manubrium. Elevation of the sternum is secured by the sutures with wire at the wedge resection site (Fig.6.). He added an external traction by fixation of a wire penetrated the caudal part of the sternum and the 5th costal cartilage with a ladder placed on the anterior chest wall.

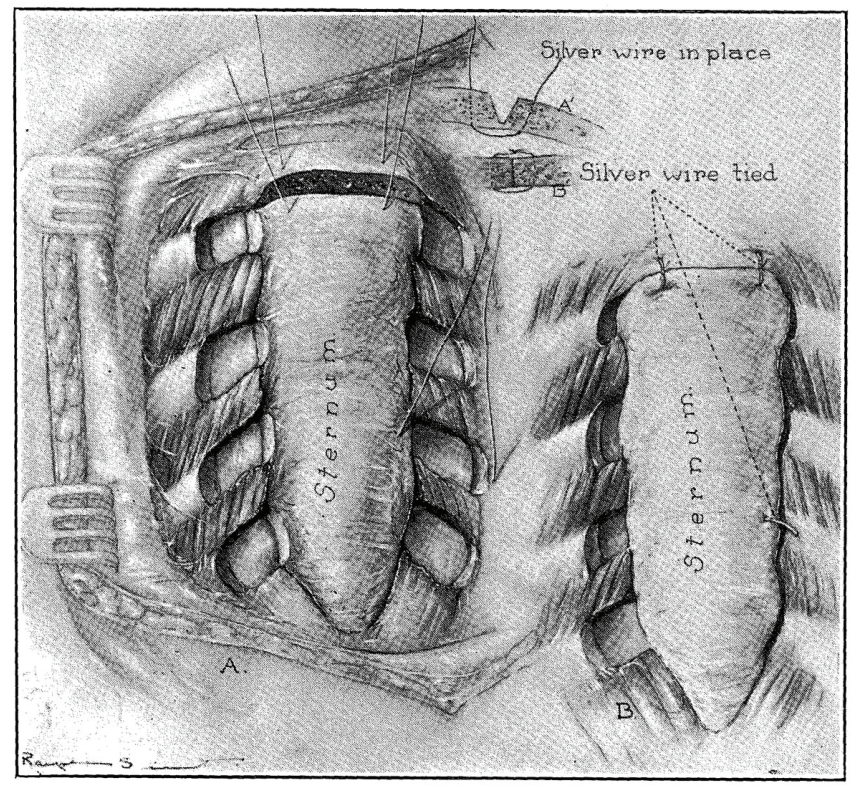

Fig. 6. The 2nd procedure of Brown (Brown, 1939) 
The Brown's procedure was took over by Sweet (Sweet, 1944), and led to the Ravitch's procedure, which will be described in the next chapter.

A variety of corrective procedures have appeared, based on various ideas. The sternal turnover method was performed by Wada and colleagues (Wada et al., 1965) in Japan. He made an isolated plastron from the anterior chest wall, and turned it over, and sutured it back in place (Fig. 7.). This procedure had been performed in many cases in Japan, but not in other countries, because it had risk of necrosis of plastron. Laituri and colleagues (Laituri et al., 2010) described that osteo-necrosis or fistula formation occurred in $46 \%$ of the patients over 15 years of age in Wada's series. And such complications prompted Taguchi to preserve the internal mammary vessels to maintain the blood flow to the sternum (cited from Laituri et al.). However, despite of such modification, sternal turnover procedure became to be performed infrequently. Recently, Ninkovic and colleagues (Ninkovic et al., 2003) planned revival of the sternal turnover procedure, using technique of vascular surgery to anastomose the internal mammary vessels, i.e., the right internal mammary vessels to the inverted left mammary vessels (Fig. 8.).

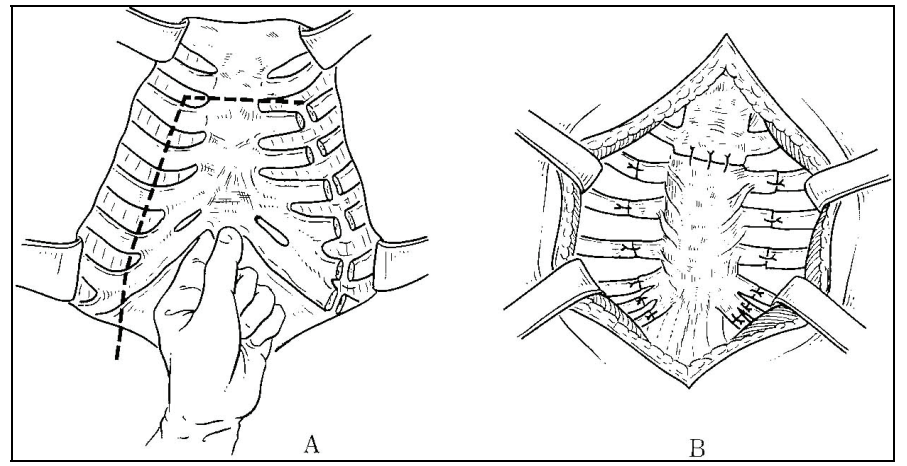

Fig. 7. “Sternoturnover" procedure (Wada et al., 1965)

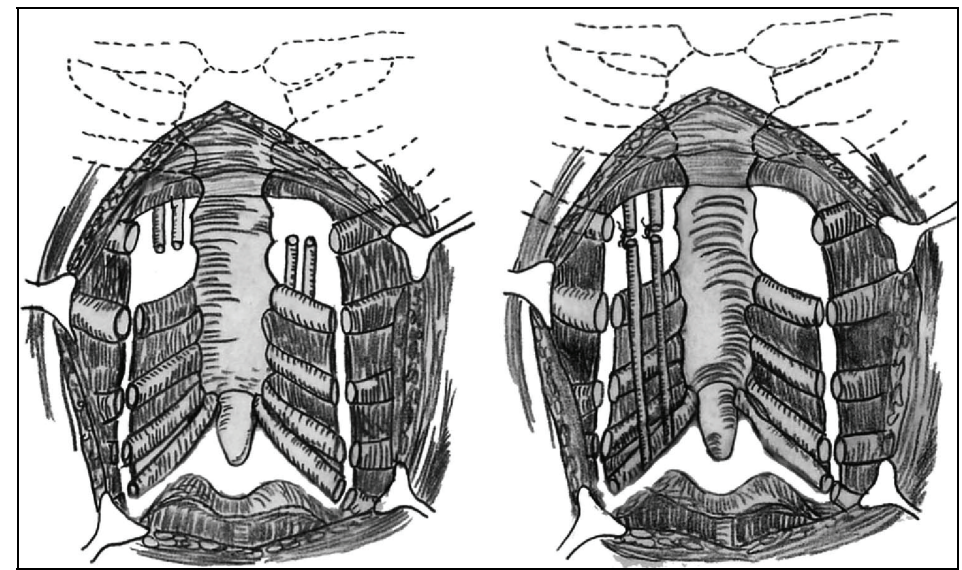

Fig. 8. Ninkovic's modification of "Sternoturnover" (Ninkovic et al., 2003)

(Reprinted with permission from Plast Reconst Surg 2003;112:1356) 
Proposals from plastic surgeons are various. In 1970, Masson and colleagues (Masson et al., 1970) implanted a preformed silastic implant, with Dacron mesh patches on it, through a transverse incision just below the xiphoid. Although 40 years passed since then, the accumulated cases were not so many. Snel and colleagues (Snel et al., 2009) summed up 75 cases from 5 papers, and showed the long term outcome results of his own 16 patients. Complications occurred in 7 patients (43\%); prolonged seroma in 5, in whom explantation of the implant were performed in one, reoperation and repositioning in 2 patients. Two patients underwent explantation of the implants due to pain and discomfort. Satisfactions of the patients were evaluated by 4 grades; excellent 1 , good 8 , mediocre 3 , and poor 1 .

Michlits and colleagues (Michlits et al., 2009) performed free fasciocutaneous infragluteal flap in 6 patients. He stated that the patients were satisfied on shape of the corrected PE. However, these plastic surgeries can not release the hearts and lungs from compression. Accordingly, they could not be indicated for symptomatic patients. Moreover, implantations of foreign body do not always provide good results.

In 1998, Nuss and colleagues (Nuss et al., 1998) advocated a new procedure "minimally invasive technique for PE". This proposal invited revolution of corrective surgery for PE. The minimally invasive operation was reinforced with various modifications, and subsequently increased the followers worldwide. Concerning this procedure, detailed description will appear in the 2.3 chapter.

Some new trials originating from new ideas appeared. Harrison and colleagues (Harrison et al., 2010) proposed Magnetic Mini-Mover Procedure (3MP). The 3MP uses a magnetic implant coupled with an external magnet to generate force sufficient to gradually remodel PE deformities. The magnimplant is set at surface of the sternum, and the magnatract is set on the rear table of the external brace, which is worn by the patient (Fig. 9.). The principle of this procedure is that the magnetic gravitation between the magnimplant and the magnatract lifts up the sternum. He performed this procedure in 10 patients, but outcome results were not yet gained. Schier and colleagues (Schier et al., 2005) proposed the vacuum chest wall lifter, which is set at anterior chest wall. Suction with this apparatus is conducted from 30 minutes to 5 hours daily, and repeated for 2 year (Fig. 10.). Reliable outcome results were not yet gained.

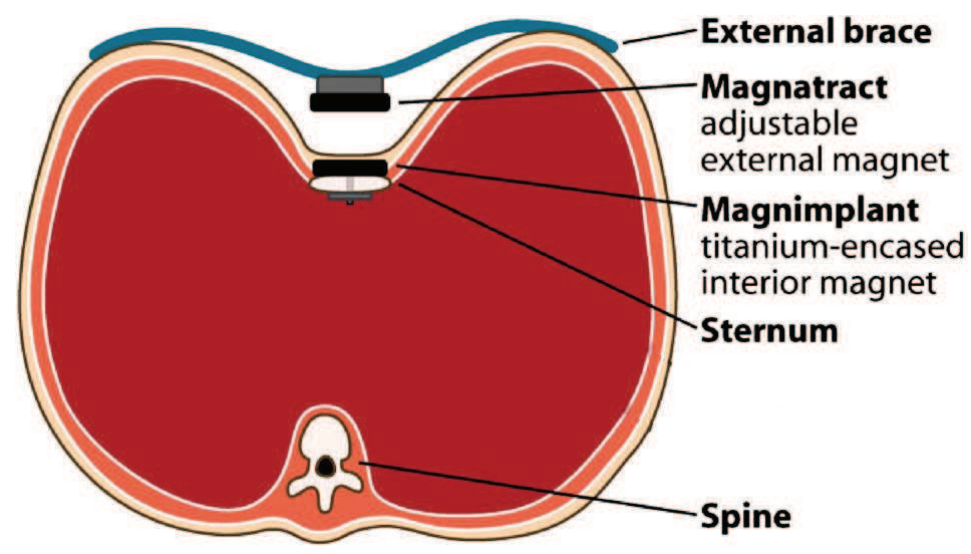

Fig. 9. Magnetic Mini-Mover Procedure (Harrison et al., 2010)

(Reprinted with permission from J Pediatr Surg 2010;45:187) 


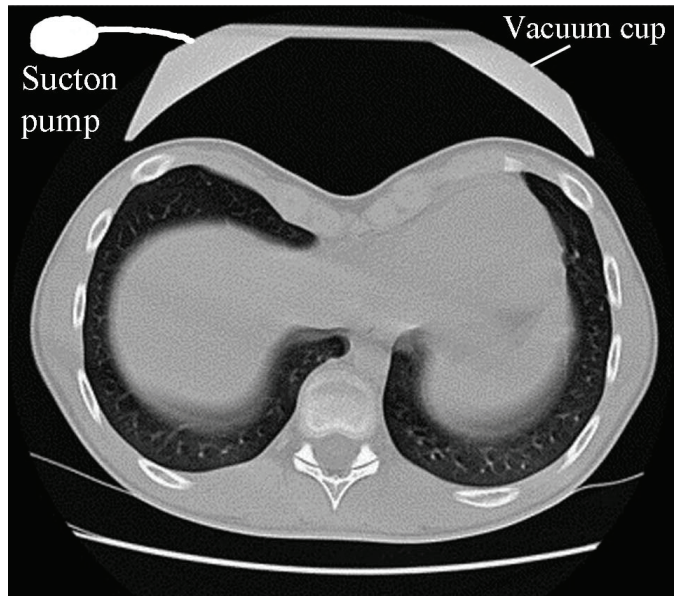

Fig. 10. The vacuum chest wall lifter (Schier, 2005)

(Reprinted with permission from J Pediatr Surg 2005;40:497)

\subsection{Ravitch's procedure (open repair)}

\subsubsection{Procedure}

In 1949, Ravitch proposed his original procedure for PE. He intended to make free the sternum from all restrictions. In order to carry out his idea, he felt it necessary to divide the xiphi-sternal articulation and substernal ligament and to resect all the deformed costal cartilages for the length of their deformity. Furthermore, to elevate the sternum, he performed a transverse cuneiform osteotomy at the sterno-manubriul junction and sutured it, to maintain the corrected position (Fig. 11.). He did not use the traction apparatus that Brown used. The extensive defect resulting from excision of all of the deformed cartilages was left without sutures of any tissues.

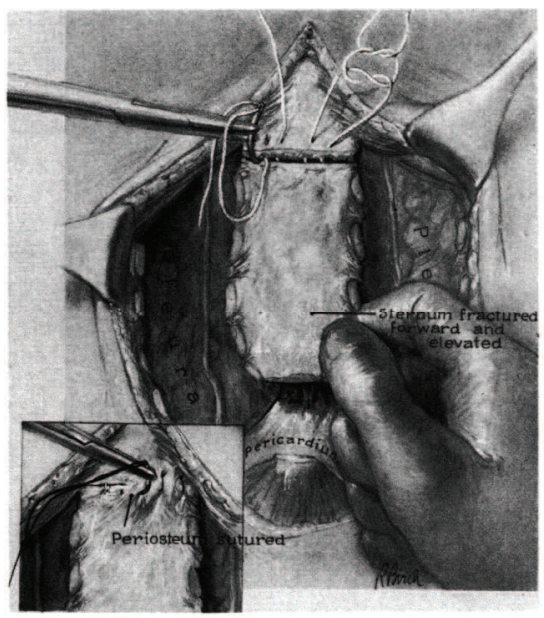

Fig. 11. Original Ravitch procedure (Ravitch, 1949)

(Reprinted with permission from Ann Surg 1949;129:434) 
In 1965, Ravitch revised his original procedure; 1) oblique chondrotomy at 2nd or 3rd costal cartilages and overlap suture (Fig. 12 a.), and 2) sternal osteotomy on the rear table of the sternum, instead of the anterior table in the original procedure, and insertion of a small bone graft in the sternal opening (Fig. 12 b.). Such modifications were done, in order to elevate the sternum more effectively and prevent recurrence of depression. At present, the procedure with the above-stated modifications i.e., 3points fixation, is denominated "Ravitch procedure".

b)

a)

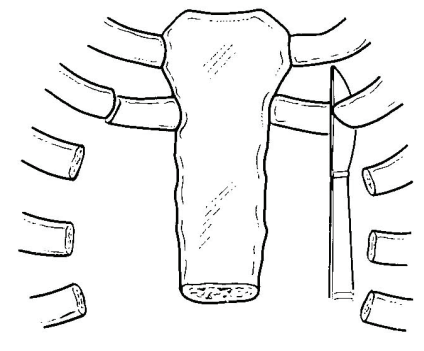

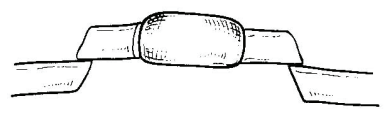

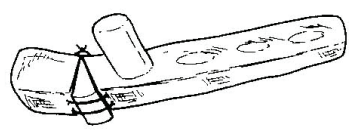

Fig. 12. Modified Ravitch procedure by himself

(Reprinted with permission from Kokyukigeka 1st ed., p. 378, Nanzan-do)

The most faithful successor to Ravitch is Alex Haller Jr. Although he took over the Ravitch procedure in general, he pointed out 2 important problems. The 1st is a fact that support of the anterior chest wall by the Ravitch procedure is not sufficient for children older than 10 years of age, teenagers, and adults. So, he performed placement of a temporary stainless steel strut beneath the sternum, and the strut is anchored bilaterally to the 5th or 6th ribs (Haller et al., 1989). The strut is removed on an outpatient basis, $6 \sim 9$ months after the primary repair.

The 2 nd is a suggestion, that too extensive and too early operation could induce chest wall constriction. The total resections of the deformed costal cartilages in Ravitch procedure resulted to remove growth center activity of costal cartilages. He recognized such severe complication in 12 children, and denominated "aquired Jeune's syndrome" (Haller et al., 1996). He corrected his procedure as follows; 1) exclusion of the children below 4 years of age from indication of the repair, 2) shortening of the resected costal cartilages by $2.5 \mathrm{~cm}$.

Fonkalsrud remarked that after the removal of deformed costal cartilages in the Ravitch's procedure, the regenerated cartilages are thin, irregular, and commonly rigid with calcification, even if the perichondrial sheaths are preserved. So, he removed short chips ( $3 \sim 8 \mathrm{~mm})$ of the costal cartilages on the medial and the lateral ends of the deformed cartilages (Fonkalsrud, 2004) (Fig. 13.). The remaining costal cartilages are reattached to the sternum and the ribs. Following to a transverse wedge osteotomy on the anterior table of the sternum and fixation of a thin stainless steel Adkins strut was placed posterior to both the sternum and the costal cartilages to elevate the sternum (Fig. 14). He evaluates this procedure as a much less extensive repair. 


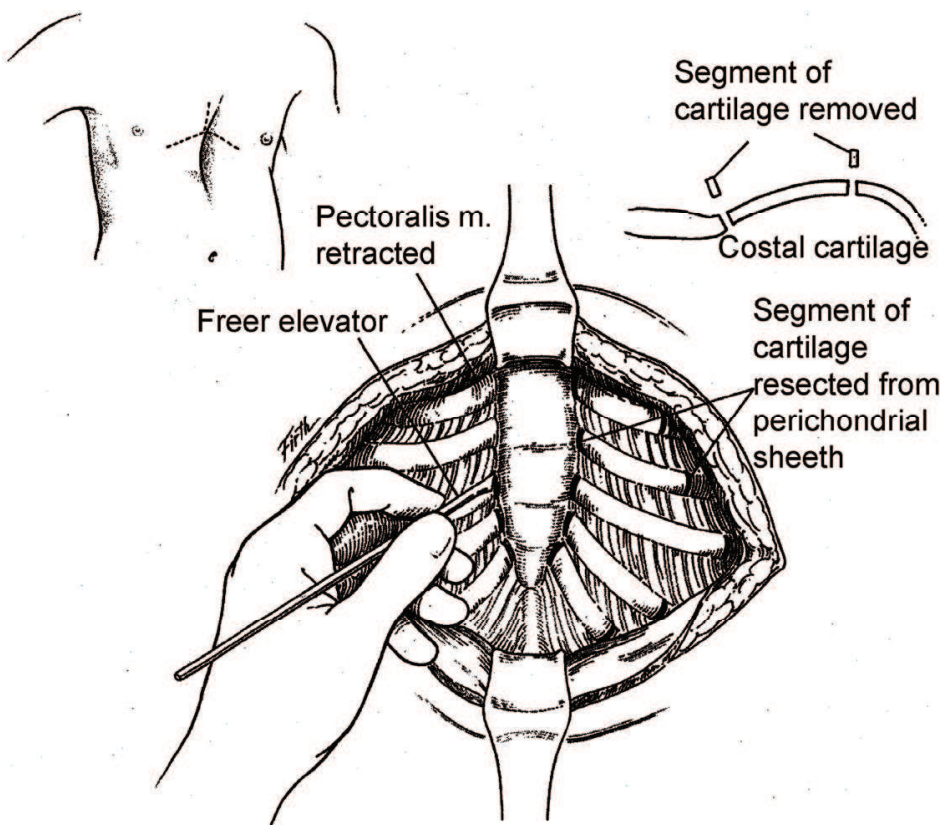

Fig. 13. Fonkalsrud's procedure (I) (Fonalsrud, 2004)

(Reprinted with permission from Ann Surg 2004;240:232)

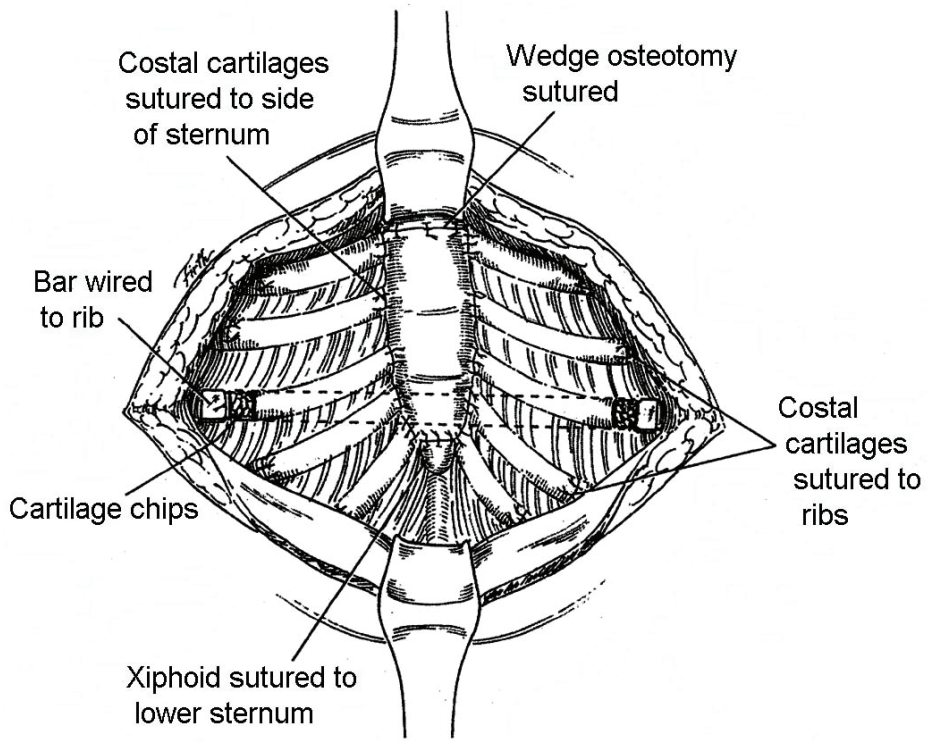

Fig. 14. Fonkalsrud's procedure (II) (Fonalsrud, 2004)

(Reprinted with permission from Ann Surg 2004;240:233) 
Robicsek hated metal materials supporting the elevated sternum, because they have the potential to leave their original position and wander all over the body. Even if the metal support remains in place, it has possibility to destroy the surrounding organ. So, he thought up a new supporting system using Marlex mesh. After wedge resection of the sternum and resection of the deformed cartilages and detachment of the xiphoid, the sternum is maintained in its corrected position by suturing a sheath of Marlex mesh taut under it (Robicsek, 2000) (Fig. 15.). Concerning the destiny of the implanted material, Robicsek stated that in 2 reoperating cases due to recurrence of depression, he found the area where the mesh was inserted to be a fibrocartilaginous plate with no identifiable traces of the mesh (Robicsek, 2009).

Saxena and Willital (Saxena \& Willital, 2007) reported 1,264 open-repair patients with the Willital-Hegemann procedure, which uses 3 struts. The 1st is passed transsternally, with its edges resting anteriorly on the ribs. The other 2 struts are set parasternally with the points of fixation being the 2nd ribs and the lowest ends of the rib cage (Fig. 16.). These struts are removed after 24 36 months. Saxena and colleagues (Saxena et al., 2007) performed the Nuss procedure in 160 patients from 2000 2006 too, and stated the open repair with Willital-Hegemann procedure should be indicated to the severe deformed patients.

$\mathrm{Hu}$ and colleagues (Hu et al., 2008) performed open repair in $398 \mathrm{PE}$ patients. His procedure consists of the resections of the deformed costal cartilages and fixation by "arch-shaped" steal strut, which is removed 1 year after the operation.

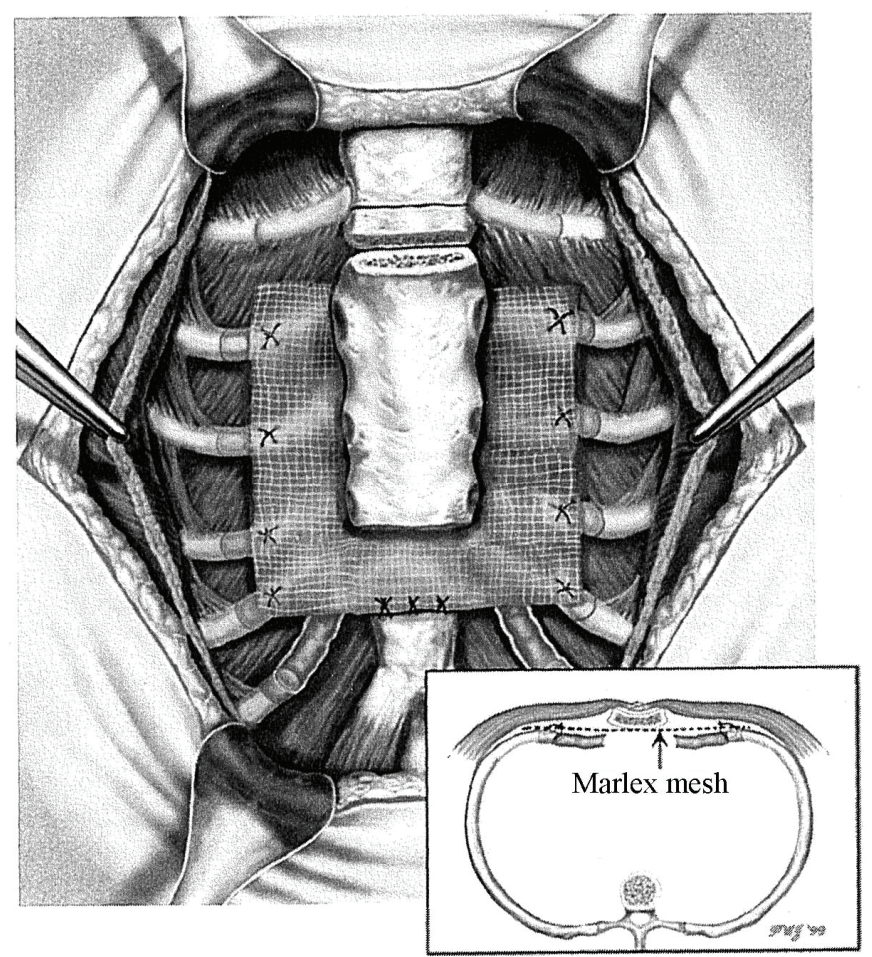

Fig. 15. Robicsek's procedure (Marlex mesh hammock) (Robicsek, 2000) 

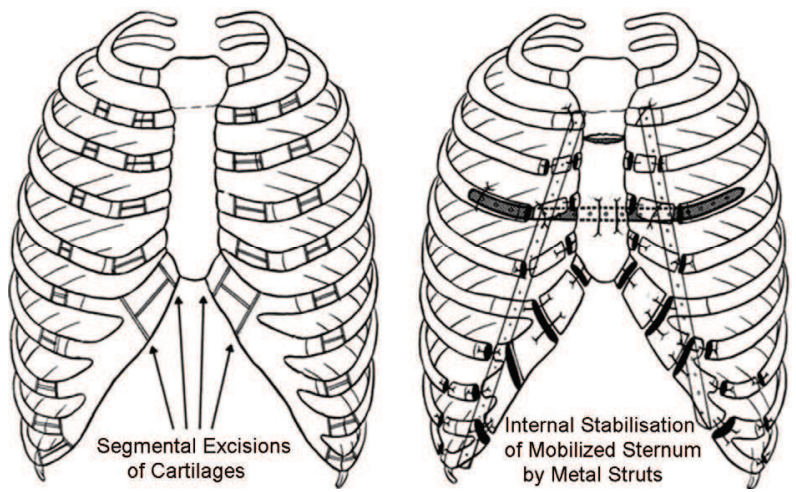

Fig. 16. Saxena \& Willital's procedure (Saxena and Willital, 2007)

(Reprinted with permission from J Thorac Cardiovasc Surg 2007;134:874)

\subsubsection{Complications and outcome results}

Table 3 shows large series of the Ravitch repair. However, the complications and the outcome results in them are not completely clear, because these reviews deal not always their complications and outcome results, besides, even if such descriptions are involved, not in uniform style. Ravitch described about 2 cases with staphylococcal infection, one of whom underwent removal of sequester, and stated no other complications except them (Ravitch, 1965).

Haller and colleagues (Haller et al., 1989) stated the morbidity rate was less than $5 \%$, and mean hospital stay was 7 days. Concerning of the outcome results, in early series during evolution of the surgical technique, reoperation occurred in $10 \%$ of the patients. However, recent series, revealed only 3 poor results in 352 patients. He stated that, therefore, the operative results with the current technique were quite satisfactory with greater than $95 \%$ of the patients having good to excellent results.

\begin{tabular}{|l|c|c|l|l|}
\hline \multicolumn{1}{|c|}{ Author } & Publish & Cases & \multicolumn{1}{c|}{ City (Nation) } & \multicolumn{1}{c|}{ Remarks } \\
\hline Ravitch & 1965 & 164 & Baltimore (USA) & Original Ravitch \\
\hline Haller & 1989 & 664 & Baltimore (USA) & Strut \\
\hline Robicsek & 2000 & 800 & Charlotte (USA) & Marlex-mesh hammock \\
\hline $\begin{array}{l}\text { Saxena and } \\
\text { Willital }\end{array}$ & 2007 & 1262 & Graz (Austria) & $\begin{array}{l}\text { Wittel-Hegeman procedure } \\
\text { (3 struts) }\end{array}$ \\
\hline Hu & 2008 & 398 & Sichuan (China) & Strut \\
\hline Fonkalsrud & 2009 & 912 & Los Angeles (USA) & Strut \\
\hline Masaoka & 2011 & 307 & Nagoya (Japan) & Metal-free \\
\hline
\end{tabular}

Table 3. Large series of Ravitch repair

Robicsek (Robicsek, 2000) stated that mean hospital stay was 3 days, and the important postoperative complications were bleeding from the internal mammary artery, infection, and seroma. However, he did not mention their frequency, as same as outcome results. Saxena and Willital (Saxena \& Willital., 2007) stated that the complication rate was 5.7\%, and hospital stay decreased from 20.5 days in early series to 6.2 days in recent series. They referred to late results, and indicated $1.4 \%$ of major recurrence and $3.6 \%$ of mild recurrence. Subjective complaints of the patients before the surgeries were eliminated in $97 \%$ of the patients. 
$\mathrm{Hu}$ and colleagues (Hu et al., 2008) had to perform early removal of metal bar due to its dislodge in 4 patients, and noticed recurrent depression in 3 patients $(0.75 \%)$, and protrusion of 2 nd or 3 rd costal cartilages in 5 patients $(1.26 \%)$. As the final results, normal contour of the costal cage was constructed in $98.74 \%$ (393/398). Cardiac function recovered to the healthy level of the same age.

Fonkalsrud (Fonkalsrud, 2009) showed $8 \%$ of complication rate. Recurrence occurred in 5 patients from series I (17\%), 15 patients from series II $(4.3 \%), 7$ patients from series III $(3 \%)$, and 4 patients from series IV $(1.3 \%)$, and total 22 patients $(2.4 \%)$ underwent reoperations. The reoperation rates have decreased in the learning curve. Satisfaction of the patients or parents was evaluated as very good or excellent by $94.2 \%$ of all patients.

Complications in our 307 patients of early series before the current procedure, which will be described in the 2.5 chapter, were $34(11.0 \%)$. The list of each complication is shown in Table 4.

\begin{tabular}{|c|c|c|c|c|c|c|c|}
\hline Series & Seroma & $\begin{array}{l}\text { Wound } \\
\text { compli- } \\
\text { cations }\end{array}$ & $\begin{array}{l}\text { Pneumo- } \\
\text { thorax }\end{array}$ & $\begin{array}{l}\text { Pleural } \\
\text { effusion }\end{array}$ & $\begin{array}{l}\text { Pulmonary } \\
\text { compli- } \\
\text { cations }\end{array}$ & Others & $\begin{array}{l}\text { Total } \\
(\%)\end{array}$ \\
\hline $\begin{array}{c}\mathrm{I} \\
(\mathrm{n}=27)\end{array}$ & 2 & \begin{tabular}{|l|} 
Dehis- \\
cence 2
\end{tabular} & 1 & & $\begin{array}{c}\text { Pneumonia } \\
1\end{array}$ & $\begin{array}{l}\text { Paradoxical } \\
\text { breathing } 1\end{array}$ & $\begin{array}{c}7 \\
(25.9)\end{array}$ \\
\hline $\begin{array}{c}\mathrm{II} \\
(\mathrm{n}=23)\end{array}$ & 1 & & 2 & & $\begin{array}{c}\text { Atelectasis } \\
1\end{array}$ & & $\begin{array}{c}4 \\
(17.4)\end{array}$ \\
\hline $\begin{array}{c}\text { III } \\
(n=117)\end{array}$ & 1 & $\begin{array}{l}\text { Wound } \\
\text { necrosis } \\
1\end{array}$ & 2 & 1 & $\begin{array}{c}\text { Atelectasis } \\
1\end{array}$ & $\begin{array}{l}\text { Ventilatory } \\
\text { insufficiency } \\
1 \\
\text { Early } \\
\text { recurrent of } \\
\text { PE } 1\end{array}$ & $\begin{array}{c}8 \\
(6.8)\end{array}$ \\
\hline $\begin{array}{l}\text { IV adult } \\
\text { type } \\
(\mathrm{n}=52)\end{array}$ & 1 & $\begin{array}{l}\text { Wound } \\
\text { infection } \\
1 \\
\text { Osteo- } \\
\text { myelitis } \\
\text { of } \\
\text { sternum } \\
1 \\
\text { Bleeding } \\
1\end{array}$ & & 1 & $\begin{array}{c}\text { Pulmonary } \\
\text { edema } 1 \\
\text { Atelectasis } \\
1\end{array}$ & $\begin{array}{l}\text { Sudden } \\
\text { death } 1 \\
\text { Respiratory } \\
\text { insufficiency } \\
2 \\
\text { Pericardial } \\
\text { effusion } 1\end{array}$ & 11 (21.1) \\
\hline $\begin{array}{l}\text { IV child } \\
\text { type } \\
(\mathrm{n}=88)\end{array}$ & & & 4 & & & & $\begin{array}{c}4 \\
(4.5)\end{array}$ \\
\hline $\begin{array}{c}\text { Total } \\
(\mathrm{n}=307)\end{array}$ & 5 & 6 & 9 & 2 & 5 & 7 & $\begin{array}{c}34 \\
(11.0)\end{array}$ \\
\hline
\end{tabular}

Table 4. Complications in early series of us

\subsection{Nuss procedure}

\subsubsection{Procedure}

In 1998, Nuss et al. proposed a new procedure - minimally invasive technique - , and assessed their 10 years results. The essence of this procedure is correction of thoracic cage by a metal bar inserted posterior to the sternum without incision or resection of costal cartilages. 
His idea was originated from observation of the thoracic deformity in the adult patients with chronic emphysematous lungs - barrel shaped thorax. He thought that, if this configuration of chest wall can occur long after their skeleton has matured and calcified, it should be possible to remodel the chest wall in children whose ribs and cartilages are still soft and pliable without having to resort to rib cartilage incision, resection, or sternal osteotomy. Detail of this procedure is as follows.

1. Preoperatively, a proper length meal bar is selected, and bent into proper convexity.

2. A transverse incision $2.5 \mathrm{~cm}$ long was made in each lateral chest wall between the anterior axillary and posterior axillary lines.

3. A skin tunnel was raised anteriorly, and $50 \mathrm{~cm}$ long Kelly clamp is inserted along an intercostal space, and advanced slowly across the mediastinum immediately under the sternum until it emerged on the opposite side (Fig. 17A.).

4. Two strands of umbilical tape were pulled through the track (Fig. 17B.). One strand serves to guide the Kelly clamp from another side.

5. When the track was deemed wide enough, a steel bar is pulled beneath the sternum using the umbilical tape for traction with the convexity facing posteriorly (Fig. 17C.).

6. When the bar is in position, it is turned over with a vice grip so that the convexity faces anteriorly (Fig. 17D.).

7. The bar is secured with heavy sutures to the lateral chest wall muscles.

8. If the bar is unstable, a $2 \sim 4 \mathrm{~cm}$ cross bar is attached to one or both ends of the bar.
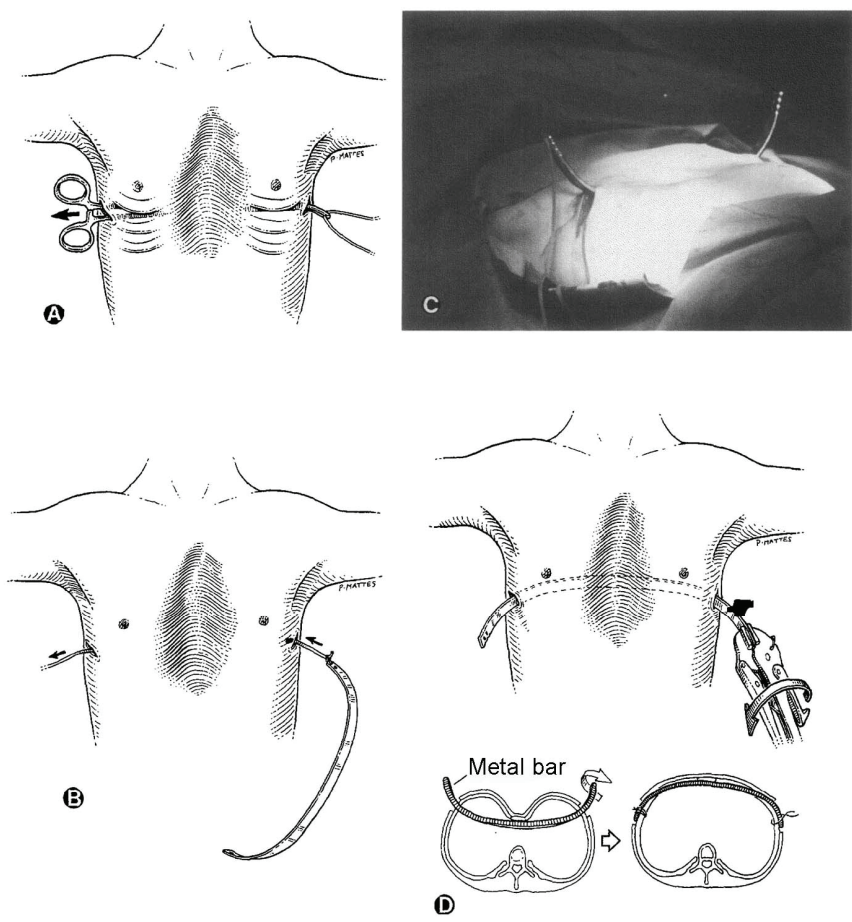

Fig. 17. Nuss procedure (Nuss et al., 1998)

(Reprinted with permission from J Pediatr Surg 1998;33:548) 
Thereafter, he modificated the original procedure, in order to avoid the injuries to vessels and bar shifts. Modifications are as follows: 1 ) use of thoracoscopy to secure the insertion of introducer, 2) use of introducer (large metal rod) to secure the tunnel making, 3) fixation of the bar with stabilizer and fixing suture (Fig. 18.). The bar is stabilized by wiring a stabilizer to the left end of the bar and by placing sutures of polydioxanone (PDS) around the bar and underlying ribs on the right end. 4) Use of two or more bars in the patients with unacceptable configuration after use of one bar.

Park and colleagues (Park et al., 2010) added 3 modifications; one of those is the crane technique. This technique involves elevating the depressed sternum before introducer insertion and lifting the wire suture along with the sternum by an operating table-mounted retractor system (Fig. 19.). This technique serves to alleviate the pressure on the bar, and to prevent internal organ injury during the passage of the introducer. The other is the morphology-tailored bar shaping system named "terrain contour matching". Each patient has distinctive terrain characteristics. Park planned to shape the bar as matched to the patient's thorax, and to compress the crest of the depression by the negative momentum of the lever action, during rotation of the bar (Fig. 20.).

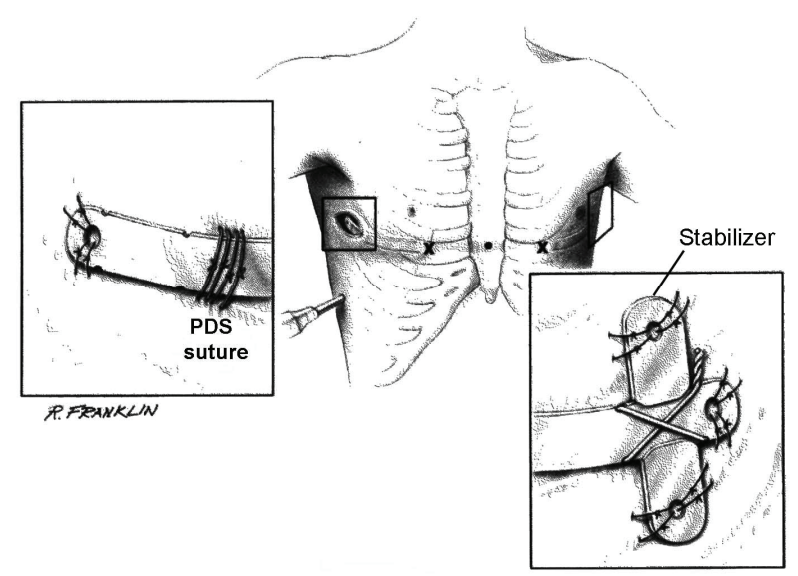

Fig. 18. Modification of Nuss procedure by Nuss (Nuss, 2005)

(Reprinted with permission from Jpn J Thorac Cardiovasc Surg 2005;53:339)

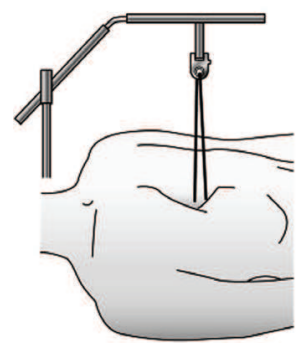

Fig. 19. Park's modification - crane technique - (Park et al., 2010)

(Reprinted with permission from J Thorac Cardiovasc Surg 2010;139:381) 

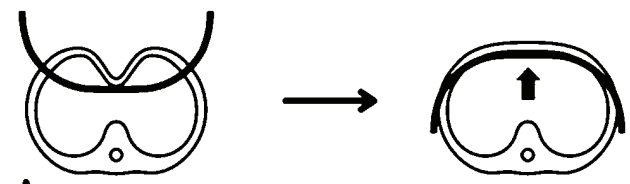

A
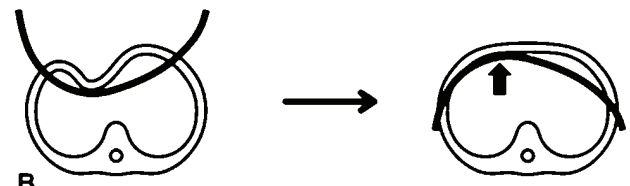

B
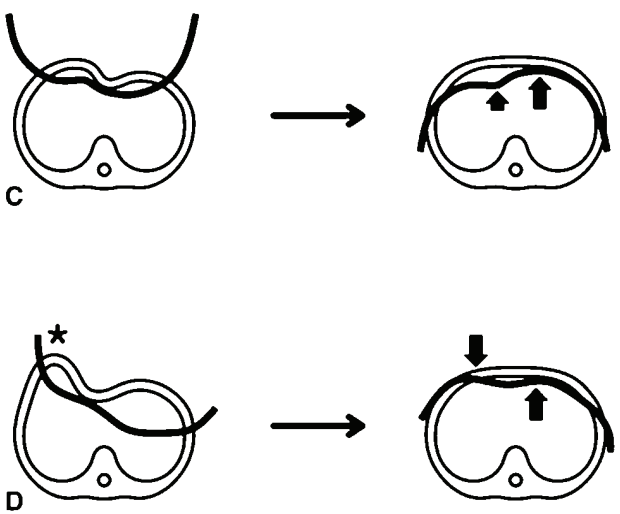

Fig. 20. Park's modification - terrain contour matching - (Park et al., 2010) (Reprinted with permission from J Thorac Cardiovasc Surg 2010;139:382)

The 3rd is the multipoint fixation of the bar. This technique consisted of fixation of the bar, not only at end of the bar, but also at hinge point. The fixation is performed by "through-the-skin" technique, i.e., the needle stick is made directly through the overlying skin, passed around the rib, and passed back through the skin. The sutured wires are grabbed via a subcutaneous dissection. The retrieved sutures are passed through the endhole of the bar and tied. This technique was developed, to prevent displacement of the bar.

Pilegaard and Licht (Pilegaard \& Licht, 2008) proposed to use absorbable stabilizer in order to avoid chronic pain and necessity of removal. However, as it break easier than the one of metal, further research is needed.

\subsubsection{Complications and outcome results}

Table 5 shows large series of the Nuss repair.

The latest report about postoperative complications after the Nuss repair in the Nuss's institute is shown in Table 6 and Table 7 (Kelly et al., 2010). In the line-up of the early 
complications, the majority is mild one, but hemothorax includes injury of internal mammary vessels. In the late complications, the majority is one concerning with the bar. The bar displacements occurred in 64 patients (5.7\%), in whom 45 patients required repositioning. Kelly and colleagues (Kelly et al., 2010) stated that the bar displacement rate was $12 \%$ in the patients without stabilizer, $6 \%$ in the patients with wired stabilizer, and with the addition of pericostal sutures placed around the bar and underlying ribs, it dropped to $2 \%$. It should be paid attention that bar allergy is found in $3.1 \%$.

\begin{tabular}{|l|c|c|l|l|}
\hline \multicolumn{1}{|c|}{ Author } & Publish & Cases & \multicolumn{1}{c|}{ City (Nation) } & \multicolumn{1}{c|}{ Remark } \\
\hline Dzielicki & 2006 & 461 & Gliwice (Poland) & Modified Nuss \\
\hline Olbrecht & 2008 & 244 & Baltimore (USA) & Modified Nuss \\
\hline Pilegaard & 2009 & 507 & Aorhus (Denmark) & $\begin{array}{l}\text { Modified Nuss } \\
\text { (Absorbable stabilizer) }\end{array}$ \\
\hline Park & 2010 & 1170 & Ansan (Korea) & Park modification \\
\hline Kelly (Nuss) & 2010 & 1215 & Norfolk (USA) & Modified Nuss \\
\hline
\end{tabular}

Table 5. Large series of Nuss repair

\begin{tabular}{|l|r|}
\hline Pneumothorax with spontaneous resolution & $64.7 \% \quad(n=727)$ \\
\hline Pneumothorax with chest tube & $4.0 \% \quad(n=45)$ \\
\hline Horner's syndrome & $15.5 \%(n=174)$ \\
\hline Drug reaction & $3.2 \%(n=36)$ \\
\hline Suture site infection & $1.0 \% \quad(n=11)$ \\
\hline Pneumonia & $0.5 \%(n=6)$ \\
\hline Hemothorax & $0.5 \%(n=6)$ \\
\hline Pericarditis & $0.5 \%(n=5)$ \\
\hline Pleural effusion (requiring drainage) & $0.3 \%(n=3)$ \\
\hline Death & $0 \%$ \\
\hline Cardiac perforation & $0 \%$ \\
\hline
\end{tabular}

Table 6. Early postoperative complications of primary surgical patients (Kelly et al., 2010) (Reprinted with permission from Ann Surg 2010;252:1076)

\begin{tabular}{|l|r|}
\hline Bar displacements - total & $64 / 1123(5.7 \%)$ \\
\hline Bar displacements requiring revision & $45 / 1123(4.0 \%)$ \\
\hline Overcorrection (none required surgery) & $41 / 1123(3.7 \%)$ \\
\hline Bar allergy (3 required bar removal) & $35 / 1123(3.1 \%)$ \\
\hline Recurrence & $11 / 1123(1.0 \%)$ \\
\hline Bar infection - total & $6 / 1123(0.5 \%)$ \\
\hline Bar infection - required early removal & $3 / 1123(0.3 \%)$ \\
\hline Hemothorax (post-traumatic) & $4 / 1123(0.4 \%)$ \\
\hline Lactosorb stabilizer inflammation & $4 / 1123(0.4 \%)$ \\
\hline
\end{tabular}

Table 7. Late postoperative complications (Kelly et al., 2010) (Reprinted with permission from Ann Surg 2010;252:1076) 
Park and colleagues (Park et al., 2010) reported decrease of the complications, comparing the results of 1999 2002 and 2006 2008, as follows: total complications $(57 / 335,17.0 \%$ vs $33 / 394,7.5 \%)$ pneumothorax $(25 / 335,7.5 \%$ vs $3 / 394,0.8 \%)$, bar displacement $(13 / 335,3.8 \%$ vs $2 / 394,0.5 \%)$. The reoperation rate also decreased (17/335, 5.1\% vs $3 / 394,0.8 \%)$.

Pilegaard and colleagues (Pilegaard et al., 2008) noticed in his series of 383 patients, pneumothorax in $178(49 \%)$, bleeding in 2, pleural effusion in 4, seroma in 11, and deep infection in 8 . Seven patients were reoperated because of the bar dislocation $(1.8 \%)$. In another 13 patients, the stabilizer was removed because of pain.

However, the most important and characteristic complication in the Nuss procedure is massive hemorrhage due to injury of heart or great vessels (Bouchard et al., 2009; Aydemir et al., 2011). This complication is sometimes life-threatening and requires an emergency operation. It might occur during the initial operation, or in the late period of the postoperative course, or during bar removal (Jemielity et al., 2011; Haecker et al., 2009). Despite of various measures, this complication has occurred still.

Mean hospital stay is about 3 days, and the bar is removed after 2 4years, in most institutes performing the Nuss procedure.

The outcome results in the latest paper of the Nuss group are shown in Table 8 . Evaluation was made, based on grades of satisfaction of the patients or the parents. Excellent results were gained in 85.3\% (Kelly et al., 2010). They compared the preoperative and the postoperative pulmonary function data, and pointed out improvement in FVC ( $88 \%$ to $92 \%, \mathrm{p}<0.001), \mathrm{FEV}_{1}(83 \%$ to $88 \%, \mathrm{p}=0.01)$, and $\mathrm{FEF}_{25 \%-75 \%}$ ( $81 \%$ to $87 \%, p=$ not significant). They performed echocardiogram in the preoperative patients, and found mitral valve prolapse (MVP) in 216 patients (18\%). Forty-four patients with preoperative MVP underwent echocardiogram after surgery, and $20(44 \%)$ had resolution of the MVP.

Park and colleagues (Park et al., 2010) evaluated the operative results by CT indices: The Haller index changed from $6.05 \pm 11.82$ to $2.76 \pm 0.49$ ( $p<0.001$ ); the depression index changed from $1.95 \pm 1.71$ to 1 ( $\mathrm{p}<0.001)$; and the asymmetry index changed from $1.08 \pm 0.05$ to $1.02 \pm 0.02$ $(\mathrm{p}<0.001)$.

\begin{tabular}{|l|r|}
\hline Total number of primary patients & 1123 \\
\hline Total number with bar removed & 790 \\
- Excellent result & $674(85.3 \%)$ \\
- Good result & $83(10.5 \%)$ \\
- Fair result & $11(1.4 \%)$ \\
- $\quad$ Poor result & $6(0.8 \%)$ \\
- & $11(1.4 \%)$ \\
\hline
\end{tabular}

Table 8. Results after bar removal median follow-up 854 days post bar removal (Kelly et al., 2010)

(Reprinted with permission from Ann Surg 2010;252:1076) 


\subsection{Pros and cons for both procedures}

The Nuss procedure has merits, such as minimal operative wound, lesser operation time, and lesser blood loss, but simultaneously some demerits, such as frequent occurrence of complications, burden of bar(s) for a long time, and necessity of operation for removal of the $\operatorname{bar}(\mathrm{s})$.

On the other hand, the open procedure has merits, such as safety and certainly of manipulation under direct vision, and demerits, such as longer operative time, and larger operation wound.

However, there are only few papers comparing the results of both procedures, because the institutes performing both procedures are limited. Fonkalsrud and Hebra (Fonkalsrud et al., 2002) compared 68 Nuss and 139 open repairs in UCLA and South Carolina University, and concluded that the open repair needed longer operating time, but decreased hospital stay, complication rates, and use of pain medications.

Nasr and colleagues (Nasr et al., 2010) reviewed 9 papers performing both procedures, and showed no difference with respect to overall complication and patient's satisfaction. However, the rate of reoperation was higher in the Nuss Procedure.

On the other hand, Robicsek argued against the Nuss procedure (Robicsek \& Hebra, 2009). He asserted, how the two $3 \sim 4 \mathrm{~cm}$ cuts (plus the hole for the videoscope) are shorter than the wound of the open repair, and how the Nuss repair is called "minimally invasive", in which a metal bar (or bars) is driven through both pleural cavities, passed by the width of a hair between the heart and the sternum and left there for long time, and then 2 years later the same procedure is performed in "reverse". Furthermore, he was worried, how the Nuss bars may affect the costal cartilages of the growing child?

Hebra argued that the "minimally invasive" implies achievement of correction without the large incisions and the removal of bone or cartilage, and frequent occurrence of the complications was related to early experience, so the Nuss procedure has eliminated majority of complications by refinement of the procedure.

\subsection{Metal-free procedure}

As described above, all institutes of the Nuss repair and almost institutes of the Ravitch repair use metal bar. Certainly, it can keep configuration of the thorax more rigidly than the other materials.

However, it has some shortcomings; 1) possibility to injure the surrounding organs by compression, 2) displacement requiring reoperation, 3) necessity of removal, 4) pain due to long time burden, 5) growth inhibition of the thorax, 6) metal allergy and 7) possibility of recurrence of depression after removal.

The bar is left at the thoracic wall during 2 4 years in the Nuss procedure, and during $6 \sim 12$ months in the Ravitch procedure. The longer the duration of bar burden is, the higher the incidence of complications increases.

Accordingly, the metal-free procedures for PE have been tried in some institutes. Hayashi and Maruyama (Hayashi \& Maruyama, 1992) used autologous rib with preserved anterior intercostalis branch of the internal mammary artery in 3 cases. The sternoturnover procedure has been performed in minimal cases of limited institutes (Iida et al., 2010; Ninkovic et al., 2003).

On the other hand, trials using artificial materials to support the elevated sternum have been performed, too. Lane-Smith and colleagues (Lane-Smith et al., 1994) used tubular 
Dacron vascular graft, which usually $10 \mathrm{~mm}$ in width, was sutured to the 4 th or 5 th ribs. Robicsek and colleagues (Robicsek et al., 2009) used Marlex sheet as a hammock, as described earlier. Although Robicsek and colleagues performed this procedure in many patients, outcome results are not shown. Länsman and colleagues (Länsman et al., 2002) tried bioabsorbable polylactide plate as a strut, but this procedure was not performed continuously.

Masaoka and colleagues (Masaoka et al., 2011) developed a new procedure without metal bar, which reconstructs the bony thorax with support of the bridge constructed by autologous costal cartilages. Core of this procedure is as follows.

1. Subperichondrial transection of abnormally deformed $3 \mathrm{rd} \sim 7 \mathrm{th}$ costal cartilages at $1 \mathrm{~cm}$ lateral to the sternum bilaterally.

2. Removal of about $1 \mathrm{~cm}$ long deformed cartilages lateral to the cut points. The 8 th cartilages are shortened by several centimeters, in order to prevent protrusion of costal arch.

3. Transverse transection of the sternum at level of the lower border of the 4th rib.

4. Ligations and transections of the bilateral aa. et vv. thoracia interna.

5. Isolation of the sternum from the mediastinal structures and pleura. At that time, attention should be paid to preservation of the cranial parts of the internal thoracic vessels.

6. Transection of 4 th to 2 nd intercostal muscles.

7. Transverse osteotomy on the rear table of the sternum at the 2nd rib level, and gentle fracture to sternal elevation.

8. The caudal part of the sternum is detached from the 5th to 7 th intercostal muscle bundles just at the margin of the sternum.

9. The caudal part of the sternum is resected transversely in width corresponding to the 5 th costal cartilage, in order to shorten the overlong sternum.

10. The 4th or 5th costal cartilage is attached to the contralateral one at midline, in somewhat tense condition. This bridge contributes as a strut supporting the sternum. Selection of the 4 th or 5 th costal cartilage depends on the level of the sternum having contact with the bridge, i.e., caudal part of sternum.

11. Anteriorly to the bridge, both ends of the sternum are sutured by five $1-0$ absorbable threads.

12. a) In cases, in which the bridge is constructed with the 5th costal cartilage, the 3rd, 4th and 6th costal cartilages on vertebral side are trimmed up in suitable manner, and sutured to the same cartilages on sternal side by two 1-0 absorbable threads.

13. b) In cases, in which the bridge is constructed with the 4th costal cartilages, the 5th costal cartilages on vertebral side sutured to the 6th costal cartilages on sternal side. Similarly, the 6th costal cartilages on vertebral side are sutured to the 7 th costal cartilages on sternal side (Fig. 21.)

14. The 7 th costal cartilages are resected $2-3 \mathrm{~cm}$ and sutured to the sternum. Thus, the bridge of the 4th or 5th cartilages supports the caudal part of the sternum and the 6th and 7 th costal cartilages.

15. The separated bundles of the $2 \mathrm{nd}, 3 \mathrm{rd}, 4$ th intercostal muscles are sutured to the same bundles again.

16. The 6th and 7th intercostal muscles and perichondria are sutured to the reconstructed sternum. 
Fig. 22. shows the resected area. This procedure was performed in 181 child patients. About 23 years follow-up revealed complication rate of $2.8 \%(5 / 181)$, reoperation rate of $0.5 \%$ (1/181). Mean operation time is $180.6 \pm 40.6 \mathrm{~min}$, and mean blood loss is $133.6 \pm 84.8 \mathrm{ml}$. Mean hospital stay is $11.47 \pm 2.2$ days. Patient can go to school 2 weeks after operation. Participation in sporting activity is allowed after 1 month, and competitive sports are resumed after 3 months.

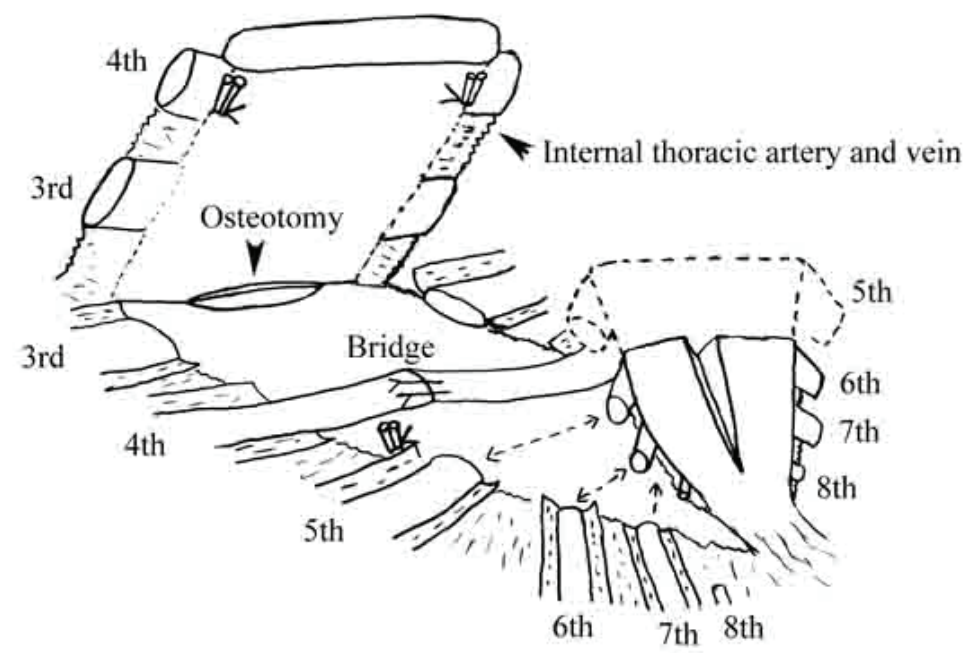

Fig. 21. Metal-free procedure (Masaoka et al., in press)

(Reprinted with permission from Eur J Cardiothorac Surg 2011, in press)
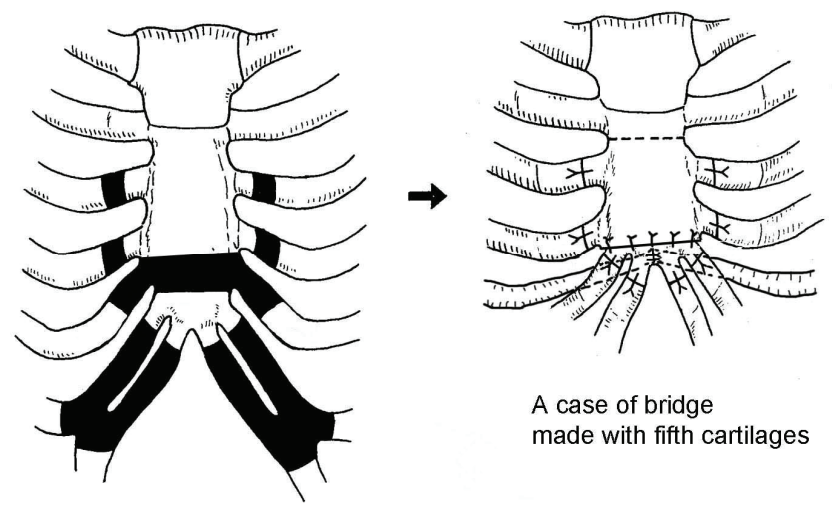

\section{A case of bridge made with fifth cartilages}

Fig. 22. Metal-free procedure.

The black area is resected.

Evaluation of correction in this operation was done by the deformity indices; Haller's, steepness, excavation volume, and asymmetry index. Table 9 shows preoperative and postoperative data. All indices improve strikingly. 


\begin{tabular}{|l|c|c|c|}
\hline \multicolumn{1}{|c|}{ Index } & Preoperative & Postoperative & $P$-value \\
\hline Haller's & $5.547 \pm 1.835$ & $4.090 \pm 1.410$ & 0.0000 \\
\hline Steepness & $0.208 \pm 0.048$ & $0.064 \pm 0.056$ & 0.0000 \\
\hline Excavation volume & $0.098 \pm 0.031$ & $0.038 \pm 0.036$ & 0.0000 \\
\hline Asymmetry & $1.105 \pm 0.171$ & $1.053 \pm 0.126$ & 0.0001 \\
\hline
\end{tabular}

Table 9. Comparison of preoperative and postoperative indices (Masaoka et al., in print) (Reprinted with permission from Eur J Thorac Cardiovasc Surg 2011, in press)

The cartilages grow together with the growth of bony thorax, and continue to support sternum. The reconstructed thoracic configurations have been kept satisfactorily during $111 \pm 51.7$ months after operations in 133 patients, excluding early postoperative (<3 years) and drop-out patients.

This procedure is indicated only to children ( $<15$ years), because of malleable character of their thorax.

Longer operation time, more bleeding and longer hospital stay are shortcomings of this procedure. However, abandon of metal bar could provide benefits that would overcome these drawbacks.

\section{Conclusion}

Throughout the history of corrective surgery for pectus excavatum, numerous procedures have been proposed, in whom 2 procedures survived and have been performed world-wide with some modifications - Ravitch and Nuss procedure-. Almost all institutes, whether Ravitch or Nuss, use metal bar to maintain configuration of the thorax. The use of metal bar has many drawbacks, i.e., frequent complications, pain, necessity of removal of bar, growth inhibition, metal allergy and possibility of recurrence of depression after removal.

A new metal-free procedure was proposed, in order to eliminate these shortcomings. Correction of thoracic configuration by this procedure was evaluated as excellent. This procedure is recommended as a standard operation for PE of children.

\section{Acknowledgement}

We appreciated the careful secretarial work by Ms Mitsuko Tenpaku in preparing this manuscript.

\section{References}

Aydemir B, Sokullu O, Hastaoglu O, Bilgen F, Celik M, Dogusoy I. Aorta-to-right ventricular fistula due to pectus bar migration. Thorac Cardiovasc Surg. 2011 Feb;59(1):51-2.

Bevegard S. Postural circulatory changes at rest and during exercise in patients with funnel chest, with special reference to factors affecting the stroke volume. Acta Med Scand. 1962 Jun;171:695-713.

Bouchard S, Hong AR, Gilchrist BF, Kuenzler KA. Catastrophic cardiac injuries encountered during the minimally invasive repair of pectus excavatum. Semin Pediatr Surg. 2009 May;18(2):66-72. 
Brown AL. Pectus excavatum (funnel chest) anatomic basis; surgical treatment of the incipient stage in infancy; and correction of the deformity in the fully developed stage. J Thorac Surg. 1939;9:164-184.

Cahill JL, Lees GM, Robertson HT. A summary of preoperative and postoperative cardiorespiratory performance in patients undergoing pectus excavatum and carinatum repair. J Pediatr Surg. 1984 Aug;19(4):430-3.

Castile RG, Staats BA, Westbrook PR. Symptomatic pectus deformities of the chest. Am Rev Respir Dis. 1982 Sep;126(3):564-8.

Creswick HA, Stacey MW, Kelly RE Jr, Gustin T, Nuss D, Harvey H, Goretsky MJ, Vasser E, Welch JC, Mitchell K, Proud VK. Family study of the inheritance of pectus excavatum. J Pediatr Surg. 2006 Oct;41(10):1699-703.

Eguchi T, Sasaki S, Hara F, Kondo S, Masaoka A. Natural course of thoracic deformity in pectus excavatum. Shonika 1993;34:61-65. (In Japanese)

Fabricius J, Davidsen HG, Hansen AT. Cardiac function in funnel chest; twenty-six patients investigated by cardiac catheterization. Dan Med Bull. 1957 Dec;4(8):251-7.

Fonkalsrud EW, Beanes S, Hebra A, Adamson W, Tagge E. Comparison of minimally invasive and modified Ravitch pectus excavatum repair. J Pediatr Surg. 2002 Mar;37(3):413-7.

Fonkalsrud EW. Open repair of pectus excavatum with minimal cartilage resection. Ann Surg. 2004 Aug;240(2):231-5.

Fonkalsrud EW. 912 open pectus excavatum repairs: changing trends, lessons learned: one surgeon's experience. World J Surg. 2009 Feb;33(2):180-90.

Haecker FM, Berberich T, Mayr J, Gambazzi F. Near-fatal bleeding after transmyocardial ventricle lesion during removal of the pectus bar after the Nuss procedure. J Thorac Cardiovasc Surg. 2009 Nov;138(5):1240-1.

Haller JA Jr, Kramer SS, Lietman SA. Use of CT scans in selection of patients for pectus excavatum surgery: a preliminary report. J Pediatr Surg. 1987 Oct;22(10):904-6.

Haller JA Jr, Scherer LR, Turner CS, Colombani PM. Evolving management of pectus excavatum based on a single institutional experience of 664 patients. Ann Surg. 1989 May;209(5):578-82; discussion 582-3.

Haller JA Jr, Colombani PM, Humphries CT, Azizkhan RG, Loughlin GM. Chest wall constriction after too extensive and too early operations for pectus excavatum. Ann Thorac Surg. 1996 Jun;61(6):1618-24; discussion 1625.

Haller JA Jr, Loughlin GM. Cardiorespiratory function is significantly improved following corrective surgery for severe pectus excavatum. Proposed treatment guidelines. J Cardiovasc Surg (Torino). 2000 Feb;41(1):125-30.

Harrison MR, Curran PF, Jamshidi R, Christensen D, Bratton BJ, Fechter R, Hirose S. Magnetic Mini-Mover Procedure for pectus excavatum II: initial findings of a food and drug administration-sponsored trial. J Pediatr Surg. 2010 Jan;45(1):185-91; discussion 191-2.

Hayashi A, Maruyama Y. Vascularized rib strut technique for repair of pectus excavatum. Ann Thorac Surg. 1992 Feb;53(2):346-8.

Hu TZ, Li Y, Liu WY, Wu XD, Feng JX. Surgical treatment of pectus excavatum: 30 years 398 patients of experiences. J Pediatr Surg. 2008 Jul;43(7):1270-4. 
Iida $\mathrm{H}$, Sunazawa T, Ishida K, Doi A. Surgical repair of pectus excavatum not requiring exogenous implants in 113 patients. Eur J Cardiothorac Surg. 2010 Feb;37(2):316-21.

Jemielity M, Pawlak K, Piwkowski C, Dyszkiewicz W. Life-threatening aortic hemorrhage during pectus bar removal. Ann Thorac Surg. 2011 Feb;91(2):593-5.

Kelly RE Jr. Pectus excavatum: historical background, clinical picture, preoperative evaluation and criteria for operation. Semin Pediatr Surg. 2008 Aug;17(3):181-93.

Kelly RE Jr, Goretsky MJ, Obermeyer R, Kuhn MA, Redlinger R, Haney TS, Moskowitz A, Nuss D. Twenty-one years of experience with minimally invasive repair of pectus excavatum by the Nuss procedure in 1215 patients. Ann Surg. 2010 Dec;252(6):107281.

Kotzot D, Schwabegger AH. Etiology of chest wall deformities--a genetic review for the treating physician. J Pediatr Surg. 2009 Oct;44(10):2004-11.

Laituri CA, Garey CL, St Peter SD. Review of the technical variants in the repair of pectus excavatum. Eur J Pediatr Surg. 2010 Jul;20(4):217-21.

Lane-Smith DM, Gillis DA, Roy PD. Repair of pectus excavatum using a Dacron vascular graft strut. J Pediatr Surg. 1994 Sep;29(9):1179-82.

Länsman S, Serlo W, Linna O, Pohjonen T, Törmälä P, Waris T, Ashammakhi N. Treatment of pectus excavatum with bioabsorbable polylactide plates: preliminary results. $J$ Pediatr Surg. 2002 Sep;37(9):1281-6.

Lawson ML, Mellins RB, Tabangin M, Kelly RE Jr, Croitoru DP, Goretsky MJ, Nuss D. Impact of pectus excavatum on pulmonary function before and after repair with the Nuss procedure. J Pediatr Surg. 2005 Jan;40(1):174-80.

Lawson ML, Mellins RB, Paulson JF, Shamberger RC, Oldham K, Azizkhan RG, Hebra AV, Nuss D, Goretsky MJ, Sharp RJ, Holcomb GW 3rd, Shim WK, Megison SM, Moss RL, Fecteau AH, Colombani PM, Moskowitz AB, Hill J, Kelly RE Jr. Increasing severity of pectus excavatum is associated with reduced pulmonary function. $J$ Pediatr. 2011 Aug; 159(2):256-61.e2.

Malek MH, Fonkalsrud EW, Cooper CB. Ventilatory and cardiovascular responses to exercise in patients with pectus excavatum. Chest. 2003 Sep;124(3):870-82.

Masaoka A, Kondo S, Sasaki S, Hara F, Mizuno T, Yamakawa Y, Kobayashi T, Fujii Y. Thirty years experience of open repair surgery for pectus excavatum -Development of a metal-free procedure-. Eur J Cardiovasc Surg 2011 (in press)

Masson JK, Payne WS, Gonzalez JB. Pectus excavatum: use of preformed prosthesis for correction in the adult. Case report. Plast Reconstr Surg. 1970 Oct;46(4):399-402.

Michlits W, Windhofer C, Papp C. Pectus excavatum and free fasciocutaneous infragluteal flap: a new technique for the correction of congenital asymptomatic chest wall deformities in adults. Plast Reconstr Surg. 2009 Nov;124(5):1520-8.

Nakahara K, Ohno K, Miyoshi S, Maeda H, Monden Y, Kawashima Y. An evaluation of operative outcome in patients with funnel chest diagnosed by means of the computed tomogram. J Thorac Cardiovasc Surg. 1987 Apr;93(4):577-82.

Nakaoka T, Uemura S, Yano T, Nakagawa Y, Tanimoto T, Suehiro S. Does overgrowth of costal cartilage cause pectus excavatum? A study on the lengths of ribs and costal cartilages in asymmetric patients. J Pediatr Surg. 2009 Jul;44(7):1333-6.

Nakaoka T, Uemura S, Yoshida T, Tanimoto T, Miyake H. Overgrowth of costal cartilage is not the etiology of pectus excavatum. J Pediatr Surg. 2010 Oct;45(10):2015-8. 
Nasr A, Fecteau A, Wales PW. Comparison of the Nuss and the Ravitch procedure for pectus excavatum repair: a meta-analysis. J Pediatr Surg. 2010 May;45(5):880-6.

Ninkovic M, Schwabegger A, Gardetto A, Moser-Rummer A, Rieger M, Ninkovic M, Rainer C. Free sternum turnover flap for correction of pectus excavatum deformity. Plast Reconstr Surg. 2003 Oct;112(5):1355-61.

Nuss D, Kelly RE Jr, Croitoru DP, Katz ME. A 10-year review of a minimally invasive technique for the correction of pectus excavatum. J Pediatr Surg. 1998 Apr;33(4):54552.

Nuss D. Recent experiences with minimally invasive pectus excavatum repair "Nuss procedure". Jpn J Thorac Cardiovasc Surg. 2005 Jul;53(7):338-44.

Nuss D. Minimally invasive surgical repair of pectus excavatum. Semin Pediatr Surg. 2008 Aug;17(3):209-17.

Nuss D, Kelly RE Jr. Minimally invasive surgical correction of chest wall deformities in children (Nuss procedure). Adv Pediatr. 2008;55:395-410.

Park HJ, Jeong JY, Jo WM, Shin JS, Lee IS, Kim KT, Choi YH. Minimally invasive repair of pectus excavatum: a novel morphology-tailored, patient-specific approach. J Thorac Cardiovasc Surg. 2010 Feb;139(2):379-86.

Peterson RJ, Young WG Jr, Godwin JD, Sabiston DC Jr, Jones RH. Noninvasive assessment of exercise cardiac function before and after pectus excavatum repair. J Thorac Cardiovasc Surg. 1985 Aug;90(2):251-60.

Pilegaard HK, Licht PB. Early results following the Nuss operation for pectus excavatum--a single-institution experience of 383 patients. Interact Cardiovasc Thorac Surg. 2008 Feb;7(1):54-7.

Pilegaard HK, Licht PB. Can absorbable stabilizers be used routinely in the Nuss procedure? Eur J Cardiothorac Surg. 2009 Apr;35(4):561-4.

Ravitch MM. The Operative Treatment of Pectus Excavatum. Ann Surg. 1949 Apr;129(4):42944.

Ravitch MM. Technical problems in the operative correction of pectus excavatum. Ann Surg. 1965 Jul;162:29-33.

Robicsek F. Surgical treatment of pectus excavatum. Chest Surg Clin N Am. 2000 May;10(2):277-96.

Robicsek F, Watts LT, Fokin AA. Surgical repair of pectus excavatum and carinatum. Semin Thorac Cardiovasc Surg. 2009 Spring;21(1):64-75.

Robicsek F, Hebra A. To Nuss or not to Nuss? Two opposing views. Semin Thorac Cardiovasc Surg. 2009 Spring;21(1):85-8.

Saleh RS, Finn JP, Fenchel M, Moghadam AN, Krishnam M, Abrazado M, Ton A, Habibi R, Fonkalsrud EW, Cooper CB. Cardiovascular magnetic resonance in patients with pectus excavatum compared with normal controls. J Cardiovasc Magn Reson. 2010 Dec 13;12:73.

Saxena AK, Castellani C, Höllwarth ME. Surgical aspects of thoracoscopy and efficacy of right thoracoscopy in minimally invasive repair of pectus excavatum. J Thorac Cardiovasc Surg. 2007 May;133(5):1201-5.

Saxena AK, Willital GH. Valuable lessons from two decades of pectus repair with the Willital-Hegemann procedure. J Thorac Cardiovasc Surg. 2007 Oct;134(4):871-6. 
Schier F, Bahr M, Klobe E. The vacuum chest wall lifter: an innovative, nonsurgical addition to the management of pectus excavatum. J Pediatr Surg. 2005 Mar;40(3):496-500.

Shamberger RC, Welch KJ, Sanders SP. Mitral valve prolapse associated with pectus excavatum. J Pediatr. 1987 Sep;111(3):404-7.

Shamberger RC, Welch KJ. Cardiopulmonary function in pectus excavatum. Surg Gynecol Obstet. 1988 Apr;166(4):383-91.

Snel BJ, Spronk CA, Werker PM, van der Lei B. Pectus excavatum reconstruction with silicone implants: long-term results and a review of the English-language literature. Ann Plast Surg. 2009 Feb;62(2):205-9.

Sweet RH. Pectus excavatum: Report of two cases successfully operated upon. Ann Surg. 1944 Jun;119(6):922-34.

Wada J, Ikeda T, Iwa T, Ikeda K. Sternoturnover: An advanced new surgical method to correct funnel chest deformity. J Int Coll Surg. 1965 Jul;44:69-76. 
TOpics w

THORACIC SURGERY

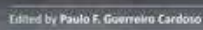

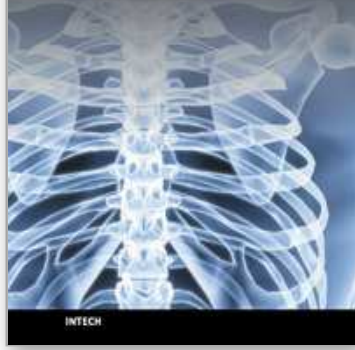

\section{Topics in Thoracic Surgery}

Edited by Prof. Paulo Cardoso

ISBN 978-953-51-0010-2

Hard cover, 486 pages

Publisher InTech

Published online 15, February, 2012

Published in print edition February, 2012

Thoracic Surgery congregates topics and articles from many renowned authors around the world covering several different topics. Unlike the usual textbooks, Thoracic Surgery is a conglomerate of different topics from Pre-operative Assessment, to Pulmonary Resection for Lung Cancer, chest wall procedures, lung cancer topics featuring aspects of VATS major pulmonary resections along with traditional topics such as Pancoast tumors and recurrence patterns of stage I lung disease, hyperhidrosis, bronchiectasis, lung transplantation and much more. This Open Access format is a novel method of sharing thoracic surgical information provided by authors worldwide and it is made accessible to everyone in an expedite way and with an excellent publishing quality.

\section{How to reference}

In order to correctly reference this scholarly work, feel free to copy and paste the following:

Akira Masaoka and Satoshi Kondo (2012). Pectus Excavatum: A Historical Perspective and a New Metal-Free Procedure, Topics in Thoracic Surgery, Prof. Paulo Cardoso (Ed.), ISBN: 978-953-51-0010-2, InTech, Available from: http://www.intechopen.com/books/topics-in-thoracic-surgery/pectus-excavatum-a-historicalperspective-and-a-new-metal-free-procedure

\section{INTECH}

open science | open minds

\section{InTech Europe}

University Campus STeP Ri

Slavka Krautzeka 83/A

51000 Rijeka, Croatia

Phone: +385 (51) 770447

Fax: +385 (51) 686166

www.intechopen.com

\section{InTech China}

Unit 405, Office Block, Hotel Equatorial Shanghai

No.65, Yan An Road (West), Shanghai, 200040, China

中国上海市延安西路65号上海国际贵都大饭店办公楼405单元

Phone: +86-21-62489820

Fax: +86-21-62489821 
(C) 2012 The Author(s). Licensee IntechOpen. This is an open access article distributed under the terms of the Creative Commons Attribution 3.0 License, which permits unrestricted use, distribution, and reproduction in any medium, provided the original work is properly cited. 